\title{
Research on Mobile Learning Model of College Computer Application Technology under the Background of Big Data
}

\author{
Huang Wei \\ Lijiang Teachers College, Lijiang, Yunnan, China
}

Keywords: Big data, Mobile learning, Cloud computing, Learning platform

\begin{abstract}
With the popularization of intelligent electronic devices, mobile learning models have become an inevitable trend. By establishing mobile learning platforms, universities can effectively make up for the problems of traditional learning methods, and reasonably introduce big data technology and Internet technology to develop computers Applied technology teaching brings out the advantages of mobile learning platforms, strengthens communication and interaction with students, and integrates with traditional classrooms to innovate teaching concepts and continuously improve teaching quality.
\end{abstract}

\section{Introduction}

At this stage, information technology is developing rapidly, and people can carry a large amount of data resources on their bodies without being limited by time and space. They can use laptops, smartphones and other devices to access Internet sites and then obtain the resources they need. It is because these mobile devices have a small amount of storage that cannot quickly update resources, and the CPU processing capacity is relatively weak. Based on the background of cloud computing and mobile networks, mobile learning models have emerged at the historic moment, and students can learn anytime, anywhere. At the same time, adding big data technology can create a more flexible learning environment for students. Students can only learn by holding mobile smart terminal devices. Using the ability of big data analysis of cloud computing, a mobile learning platform for colleges and universities can be intuitively understood. The learning habits and hobbies of students. Integrating cloud computing in a mobile environment can completely solve the problem of insufficient storage and insufficient power of portable devices. In the development process of education informatization, the mobile learning model is an important part. In the process of higher vocational education, relevant educators need to be more active in building mobile learning Platform, thus accelerating university teaching information technology development process.

\section{Mobile Learning Mode}

\subsection{Basic Features of Mobile Learning}

(1) Timeliness

The construction of mobile learning mode has strong flexibility in the time dimension. Students can use mobile learning to break through the limitations of learning place and time. As long as students have free time, they can carry out learning, which is the main advantage of mobile learning. In their free time, make corresponding learning plans and learn more knowledge. In the process, students have strong self-control.

(2) Unrestricted location

The use of intelligent communication terminals will not be limited by specific locations, but will continuously speed up the transmission and exchange of information. Use the operator's network and wireless network to learn in various places.

(3) Features of Mobile Learning Connection Method

In the process of building a mobile learning model, the connection methods mainly include the following: 1)in the Internet platform, the use of mailboxes gradually brings closer communication 
and communication between teachers and students.Educators can send student system materials to students. You can also arrange related learning tasks and assignments. Students can also use the form of email to feedback the completion of the assignments to the teacher, and closer the relationship between teachers and students. 2) Using wap technology, students can obtain in the forum platform Related learning materials. Teachers and students can also communicate in the forum. 3) Reasonably use WeChat, QQ and other communication tools, and use voice, video, text and other forms to achieve long-distance communication. This method is relatively the most flexible and convenient. .

\subsection{Demand Analysis of Mobile Learning Platform}

In the process of innovative mobile learning models in universities, the learning environment can be divided into free environments and formal environments. Based on these two environments, there are certain differences between mobile learning platforms and learning characteristics. The formal environment mainly refers to the fixed curriculum among teachers. Content teaching [1]. The use of mobile learning platforms enables online communication between teachers and students and online distribution of learning materials. After completing teaching activities, teachers can use the Internet platform to count student learning and Q \& A results. Follow-up teaching work is carried out sexually. Under the wireless campus network technology, students can use handheld mobile devices to conduct online classroom tests and review of teaching knowledge points.

Based on the free environment, students' mobile learning is relatively flexible, and based on their actual conditions, they get resources that meet the learning needs. This mobile learning method mainly includes the following two: (1) Push content and release it to students. Learning platform, teachers can push homework, content and tests suitable for different students to students' mobile devices, which is convenient for students to review. (2) Students can freely access and download from the Internet, using apps and mobile terminal browsers, and Visit the learning platform. You can download learning resources with open permissions when you are online, and students can learn while offline.

\section{Big Data Technology}

\subsection{Meaning and Category of Cloud Computing}

Big data technology mainly uses cloud computing and provides end customers with more storage space. The core idea is to provide cloud services. The basic feature is to achieve the distribution of computing tasks and obtain it from a resource pool composed of many computers. Effective information and resources. Through the dynamic demand, users cooperate with specialized software to implement centralized management of resources, reduce cost expenditures, and continuously improve use efficiency.

\subsection{Storage of Big Data}

In order to meet the actual needs of users within the specified time range, distributed massive data processing methods will be used. Relevant staff need to decompose the data and do a good job of subsequent storage. In this process, the Relying too much on low-performance computers, and doing a good job of backing up data to ensure the security of the data fundamentally.

\subsection{Virtualization Technology}

In the process of using cloud computing technology, virtual technology is an important part. It belongs to a distributed computing resource management model that can achieve the goals of storage resources and computing [2]. Using virtualization technology, various operators It can break through the limitation of physical resources and integrate into a virtual resource pool to make reasonable use of resources in all aspects. In the actual application process, virtualization technology can effectively make up for the problem of low-performance computer production capacity is too low, Utilization comes into play. 


\section{Construction of Mobile Learning Platform for College Computer Application Technology under Big Data}

\subsection{Overall Architecture}

Based on the background of big data, to build a mobile learning platform, the system architecture should be divided from top to bottom, starting from the basic support system layer, application layer, mobile access layer, and user layer, using teaching resources and wireless networks reasonably, and the overall system architecture. As shown in Figure 1.

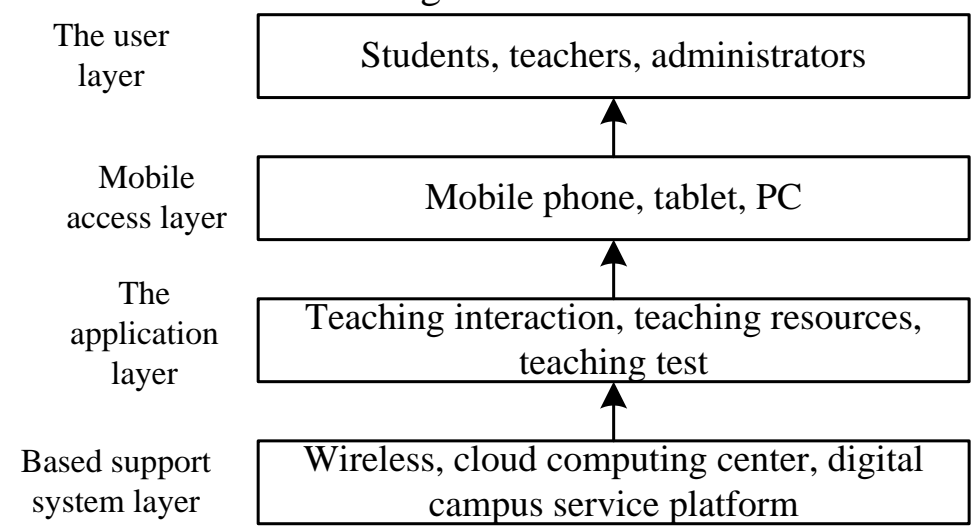

Fig.1 Overall Architecture of the Mobile Learning Platform System

The basic support system is an important support part of the entire mobile learning system, including cloud computing centers, wireless networks and digital campus service platforms. The use of wireless networks can pave the way for the construction of mobile learning models, enabling students to connect quickly Access to the wireless network and unimpeded access to the platform system. From a technical level analysis, the cloud computing center can ensure the stability of the entire system, placing applications, servers, and computing in the cloud. To bring the basic functions of the digital campus service platform into play when it comes out, it is necessary to do a good job of data management, to ensure the consistency of campus data as much as possible, and to provide services for authentication identity and data management.

In the application layer, it is mainly to integrate teaching resources, promote interaction between teachers and students, and carry out teaching test activities. In this level, strengthen the interaction and communication between the two, and provide online services. Specifically, for many Educators and students provide the required resources and provide good teacher-student communication services. One of the most important issues is that building a mobile learning platform is not just about delivering a single teaching content, but based on the basic characteristics of the mobile learning platform. Reorganize the resource library to make mobile learning more attractive.

In the user layer, combined with operating instructions and sending clear requests to the application layer, students and teachers can use terminal devices such as mobile phones and tablets, and access the network platform to learn the corresponding resources online.

\subsection{Designing Mobile Learning System Modules}

The overall architecture of the mobile learning system combined with big data calculations is analyzed and systematic module design work is carried out.It is mainly divided into the following parts: course resource management, basic service functions, mobile teaching, query services, etc.

(1) Basic Service Function Module

In the basic service function module, the main purpose is to provide the system with complete user information and carry out permissions management work. In the context of big data, using cloud computing mobile learning platform systems, using unified identity authentication, supporting multiple people to log in to the business system, and realize the management of user information [3]. The user uses a unified identity authentication platform to implement the goal of unified management, which is convenient and fast.

(2)Course Resource Management Module 
The course resource management module mainly includes courseware, lecture notes, etc., which are uploaded and integrated to integrate resources. After reviewing, the teaching resources are published on the platform to facilitate later storage and modification work and strengthen access management.

The main content of course resources are courseware, lecture notes, and teaching websites, etc., and many important information is generated during the communication process between students and teachers. Students in higher vocational colleges can reasonably use mobile learning platforms and participate in the process of course resource construction In the process of grading students' uploaded resources, through analysis and review of data, learn about the browsing and inquiry of students, and set up various storage services to adjust the uploading of resources.

(3) Mobile Teaching Management Module

In the mobile teaching management module, the main effects are to push resources, enhance teaching interaction, and carry out online testing activities. Enhancing the interaction between teachers and students is mainly to feedback the learning situation of students to teachers, so that teachers can adjust teaching Solution: In the mobile learning platform, students can display their works and ideas, and conduct discussions with classmates.

The online learning function is mainly based on cloud computing software and gradually innovates the teaching mode.Teachers can obtain corresponding data information from the cloud database, which is more convenient for students to use online learning software to learn in the construction of digital campuses [4]. This learning mode does not have high requirements for terminal equipment.It uses online testing to check the students' learning situation for a period of time, as detailed below: 1)Randomly using the information system to ask questions; 2) Teachers provide fixed test papers based on teaching progress After the learning test is completed, the system will give the evaluation results, and the evaluation results will be used to clarify the degree of students' knowledge, combined with the basic characteristics of the students, and develop effective teaching programs to help students make up for the shortcomings in learning.

(4) Query and Analysis Function Module

In the teaching process of higher vocational colleges, the mobile learning platform is introduced to provide detailed statistics and query information. Using the mobile learning platform, detailed records of resource downloading, uploading and other processes will be generated, among which a large number of logs will be generated Data information. Utilize the analysis function of the mobile learning platform to realize the integrated management of data and intuitively understand the student's learning level. Using the query and analysis module, educators can understand the student's resource downloads and login times, and the data information On the basis of this, teachers can carry out targeted teaching activities and supplement inadequate content in textbooks to meet the learning needs of students to a certain extent.

\section{Conclusion}

Based on the continuous improvement of mobile networks and big data technologies, when vocational colleges and universities carry out teaching activities, they also need to innovate teaching systems, more actively create mobile learning platforms, and then promote the development of college education informationization. At the same time of continuous development, the derivative of mobile learning has a greater impact on the learning and teaching activities of college teachers and students. Using mobile learning platforms, they can use their spare time to carry out fragmented learning. In short, in college classroom teaching to achieve complementary advantages, and to enhance the communication and exchange between teachers and students. While motivating students to learn, improve the overall teaching quality.

\section{References}

[1] Yi Shiying. Design and implementation of computer-based mobile learning app based on layered teaching. Central University for Nationalities, 2019. 
[2] Yang Bo, Zhang Xinyue, Zhang Lina. Research on Mobile Learning Mode of Computer Specialized Courses in Private Colleges and Universities. Computer and Information Technology, vol.27, no.1, pp.85-87, 2019

[3] Hu Mulan. Research on flipped classroom teaching supported by mobile learning software--Taking university computer basic courses as an example. Journal of Hebei Software Vocational and Technical College, vol.20, no.4, pp. 51-54, 2018

[4] Lu Xiaojie, Wu Xinli, Ye Mingquan. Research on mobile learning platform for computer public courses in medical universities. Computer Knowledge and Technology, vol.13, no.12, pp.95-96, 2017. 